\title{
Ontology-based interoperability solutions for textile supply chain
}

\author{
Rishad Rayyaan $\cdot$ Yi Wang $\cdot$ Richard Kennon
}

Received: 24 February 2014/ Accepted: 14 April 2014/Published online: 16 May 2014

(c) Shanghai University and Springer-Verlag Berlin Heidelberg 2014

\begin{abstract}
Existence of interoperability within the enterprises is essential for textile supply chain to efficiently face the challenges from contemporary competitors, to find new business opportunities and to render better customer service. Exchange of business documents, being semantically consistent, is the way to achieve interoperability. However, heterogeneity of the structures of the enterprises poses challenges for establishing interoperability. Ontology based semantic interoperability framework has now been proven as an effective solution for enterprise interoperability. In this paper, the existing ontology-based interoperability solutions in the context of textile supply chain have been compiled and research gaps have been identified. The ontological methods, such as unified process for ontology (UPON) and methontology have been analyzed, and UPON have been shown as a suitable ontology development method for textile supply chain.
\end{abstract}

Keywords Semantics - Ontology enterprise interoperability · Unified process for ontology (UPON) . Textile supply chain

\section{Introduction}

An integrated supply chain can fulfil certain goals of both manufacturer and supplier. It helps to reduce cost, lessen probability of duplication of efforts, reduce production lead time and reduce time to reach market. Also proper

R. Rayyaan · Y. Wang $(\bowtie) \cdot$ R. Kennon

School of Materials, The University of Manchester,

Manchester M13 9PL, UK

e-mail: yi.wang-2@manchester.ac.uk implementation of integrated supply chain increases sales volume, customer loyalty and profitability [1-4].

This integration requirement is particularly essential for textile supply chain which is spanned across the globe with plenty of small and medium enterprises (SMEs) [5]. Textile supply chain contains the flow and transformation of goods from raw material stage, up to the end users and all the pertinent information flows [6]. Supply-chain management (SCM) is the integrated approach of planning, implementing and controlling the flow of information, materials and services from the upstream enterprises processing raw materials to the downstream enterprises delivering finished products via distribution channels to the end customer. Single enterprise cannot be capable to quickly and competitively respond to the opportunities. Significant number of new production and collaboration concepts has been derived from SCM paradigm.

The activities of a supply chain are carried out by the decisions taken by the enterprise management which are divided into three decision levels namely strategic, tactical and operational [7]. Strategic level describes long-term plans such as the business scopes that depend on the structure of supply chain in a certain time period of years. Tactical decision level acts on production targets and marketing. Operational level is concerned with the daily tasks assigned to different production units. Imperfect interoperability imposes costs on the industry due to higher costs of design and production and slower implementation of design changes. These changes sometimes impose significant costs, especially for suppliers that must maintain multiple systems to satisfy the demands of multiple customers. The systems are expensive to purchase and learn. Data translator, another potential interoperability solution, currently has limited capabilities and can cause data translation errors. 
A growing number of researchers support the idea that supply chain integration can be achieved through information flow integration [8-11]. With the textile supply chain, each enterprise takes part according to their competencies and exchange data among themselves [12]. The enterprises, therefore, collaborate among themselves according to IEEE, and this collaboration is interoperable which means the abilities of two or more systems or components to exchange information and to use the information that has been exchanged [13]. Flaw of interoperability affects the quality, production, distribution and profit margin of the entire sector. Joint coordination of previously isolated individual functions of an enterprise has been one of the major challenges in exploration of opportunities for improvement of supply chain productivity, particularly since current view of supply chains is shifted from linear chains of supplier's supplier to customer's customer into complex networks.

Advancement of information and communication technology (ICTs) has introduced e-business platforms which bring many-fold advantages to the textile supply chain [5, 14]. To achieve information system interoperability, a number of solutions have been offered by IT vendors such as enterprise resource planning (ERP) solutions, supply-chain software, e-business applications to web-services, etc. [15, 16]. Analysis and usability of ERP systems have been shown in the research of Ref. [8] where they have concluded that those systems cannot provide effective integration towards different enterprises across the supply chain [17-19].

The most effective method so far has been found to be effective for different systems and data integration is ontology-based framework [7, 20-25]. Ontology establishes interoperable frameworks that seamlessly join disparate tools and agencies which work simultaneously within a particular business sector such as textile-clothing (TC) sector [12]. An ontology is defined as "an explicit specification of a conceptualisation" [26]. Ontology develops a shared understanding and by doing so, it eliminates the conceptual and terminological confusions among people, organisations or software systems who are in need to integrate or exchange data among themselves [27]. However, despite many efforts in development of interoperability frameworks, the enterprise interoperability related concepts are not yet sufficiently defined.

In this study, the focus is devoted to the ontology projects that have been applied to establish interoperability within a supply-chain domain, more specifically, within textile domain. Section 2 discusses about the interoperability projects of textile supply chain. Section 3 analyses existing approaches described in Sect. 2 to find research gaps. Section 4 reviews the ontology development methodologies used in supply chain domain. Section 5 discusses the model trial and Sect. 6 discusses about concluding remarks and few future work proposals.

\section{Review of the interoperability projects in textile supply chain}

Most of the works till 2000 were focusing on automation of internal business process. The only existing interoperability solutions were based on electronic data interchange for administration, commerce and transport (EDIFACT) $[28,29]$.

Electronic data interchange (EDI) was focused on the simplification of international commerce. It was based on a document structure for international electronic commerce, the UN dictionary of the words for international trade and the ISO syntax for the electronic transfer of data within flat files. The result of EDI project is EDIFACT which conveys a universal standard but is only affordable for large organisations. Therefore EDIFACT has not been an effective solution for SMEs [24, 25].

Between the period 1980 and 1990, a new project EDITEX developed EDIFACT subsets for the European Textile and Clothing Industry. However due to lack of flexibility, it failed to diffuse within the SMEs and was only limited to a very few large organisations [25].

Another project namely eTeXML [30] is found which is a French project, provides a set of EDI tools based on XML to allow manufacturers and retailers to implement a reactive delivery strategy.

Later on, TEX-WEAVE [31], standardization and interoperability in the textile supply chain integrated networks, is an international project that aims to provide textile sector with a framework for interoperability based on standardized electronic document exchange based on XML schemas [25].

MODA-ML is another project that came up with interoperability solution for SMEs. Aims of this project were to provide interoperability across the textile supply chains by exploiting a common interchange language based on a set of XML business components. They provide a framework with a view of peer-to-peer architecture to exchange business documents related to production process. Semantic infrastructure of the exchanged messaged is based on XML technologies and the framework is a middleware architecture based on ebXML messaging service specification and simple object access protocol (SOAP) protocol for message switching system [12]. Basing on unified process for ontology (UPON) methodology, this project creates an e-business vocabulary of XML business components and a set of public document types to support the information exchange in the supply chain. XML was used to create a sector-specific language manipulating the know-how of EDITEX [29] experience [12].

The actual project was implemented under a pilot project with few enterprises and found to be well-fitting to the actual scenario of industrial sector. One main advantage of MODA-ML was that it was very inexpensive for the 
industry to be introduced and maintained. The technological entry threshold to install and run the tools in the framework is also very low [12].

A continuation of MODA-ML is found in Ref. [24] where the researchers have defined an architecture for a document-based framework for a standardisation initiative based upon the ebXML meta-model and the ISO 11179 compliant vocabulary. They have also provided a software tool that is able to automatically extract a semantic description from the vocabulary [24].

In Ref. [14], a novel common textile vocabulary and document framework (TexVDF) in a collaborative network has been developed to enable cross-domain level business information sharing and business document exchange in a semantically consistent way. This framework presents realworld examples of business inquiries with product specifications. Within the process of developing the framework, they have developed a P2P collaborative concept mapping model and a textile business document template model [14]. These would facilitate more efficient process of enterprise engineering and integration.

Though most of the interoperability approaches focus on the exchange of production process related business documents, or product specification related documents, or purely business documents, a different project "iSURF" has proposed a framework to obtain semantic reconciliation of the planning and forecasting business documents exchanged between the companies according to different standards [32]. To achieve interoperability within the partner enterprises, they have built up a common vocabulary in exchanging the business documents. They have explained that the deployment of their systems in the textile supply chain will increase the efficiency of the supply-chain planning and consequently operational cost will be reduced.

Recently, researchers in Ref. [25] have discussed the usability and benefits of ontology with regard to establish interoperability across textile supply chain. They have developed application ontology about textile products of a specific textile factory and proposed that interoperability within the departments of that company could be achieved via the ontology. Their proposal says that if individual ontology of each department shares that thesaurus, semantic consistency can be achieved. Along with the interoperability within the departments of the enterprise, external interoperability can be achieved if the partnering enterprises develop ontologies using the same shared thesaurus. Besides, semantic search of the products via enterprise web portal is shown as another advantage that the ontology brings into that benefits customers and suppliers [25]. The higher levels of expressivity are important for the cases of very specific communication about highly focused issues of the domain.

\section{Research gap in the field of interoperability of textiles}

From the analysis of existing interoperability projects, two main research gaps have been identified in this paper. The first one is the lack of standard taxonomy about the domain relevant concepts. Secondly, lack of empirical research and evidence of quantifiable benefits of ontology-based interoperability on textile enterprises. This is one of main reasons that keeps the enterprise owners reluctant to switch to ontology based semantic interoperability approach from conventional approach [24, 25]. Another reason is leveraging the existing investments and specific requirements, which cannot be addressed by the "standard" architectures. It is even expected that, due to the increase of the data complexity and further ICT developments, the rate of the heterogeneity in the systems architecture will increase.

Filling these voids of research will result in several benefits of interoperability for streamlining the business activities of the enterprises of textile supply chain. One benefit is value proposition which defines the value that can be offered by an enterprise to another enterprise or person and leads to actual value exchange [33]. Ontology creates a value web [34] where textile enterprises can share their value propositions, and thus interoperability between manufacturer and supplier can be established.

Another benefit is the ease of product development procedure that eventually reduces the production lead time. Product development is an information processing activity which involves the product developer accessing to the repository of relevant information for processing that [35]. Ontology-based search is considered to be a possible solution to that. This will establish interoperability between manufacturer and customer. Exploiting an ontology containing the data of the development activities of customers' needs can lessen the "trial and error" steps during the development activities. Thus production lead time can be reduced. The ontologies are used in reconciliation and semantic querying process as an asset to determine or evaluate the level of interoperability. Hence the only predetermined asset, which is needed so two system can interoperate, is a common semantics.

Furthermore, automatic cost estimation is a potential application of ontology-based interoperability shown in Ref. [36]. Their empirical studies on an aluminium processing industry have inferred an application of ontology that is automatic cost estimation. This concept can be adopted on textile supply chain domain where all the suppliers involved in the product life cycle will share their cost related data using the common document template extracted from ontology. Thus intra-enterprise interoperability along with supplier-manufacturer interoperability can be achieved. 
4 Review of the ontologies built for providing interoperability in textile supply chain

In Ref. [8], existing supply chain ontologies are identified using the following keywords to search the data bases: "data model", "meta model", "information model", "ontology", "ontology model", "semantic model", "logistic model", "logistics", "supply chain", "supply chain management", "value chain" and "enterprise". After the analysis, they select six ontology models.

Other than these six methodologies, another widely accepted methodology, namely "methontology" was proposed by Fernandez et al. [37]. This methodology was first used to develop a ontology within the domain of chemical elements and crystalline structures [37]. Basing on "methontology", an ontology model having extended features from "methontology" was proposed by Munoz et al. [7] later on within the domain of chemical batch processing to provide information integration across the supply chain for the ease of decision making. The granularity of this model covers strategic, tactical and operational level of supply chain [7].

IEEE 1074-1995 [38] describes a set of standard activities that need to be present within a software framework. These activities include project management processes, project development processes and integral processes. An analysis was conducted by Fernandez et al. [37], where it was shown that methontology did not comply with the IEEE 1074-1995 standard. Later on Rajpathak and Chougule [39] presented an ontology model which included full coverage to the IEEE standard. Two applications were reported on their research paper relating to automotive industry domain and shop-floor management domain.

Methontology has not been found to be used for building ontologies within textile domain so far, yet it is considered to be a widely accepted method for ontology development for other supply chain domains, such as chemical batch processing. In most cases, the outsider will not understand the communication between two domain experts. The human reasoning of an unknown term is done by attempting to refer to the known related concepts.

Till to date, few researches are found which focus directly on textile supply chain domain to provide ontological support for interoperability. One of them is MODA-ML project where ontology is developed focusing on the e-business vocabulary. With support of the ontology based framework, enterprises can exchange business documents. This ontology was also built following UPON methodology [12, 25].

Further extension of MODA-ML is found in the research of De Sabbata et al. [24]. They have developed an ontology of business terms, based on a similar methodology of UPON, in the context of textile supply chain SMEs. The ontology is derived from a vocabulary defined by a CEN/
ISSS initiative to build a European standard of this sector. The project aims to provide semantic description of a document-based interoperability framework for business collaboration.

iSURF is another project where Dogac et al. [32] developed an ontology, starting from a common vocabulary in business document exchange, aiming to provide semantic interoperability of the planning and forecasting business documents exchanged between the companies.

Later on Duque et al. [25] used UPON methodology [40] for developing an ontology about textile products of a company. The benefits it had brought about the textile domain were establishing internal interoperability among different departments of the factory and providing an option for semantic searches via the enterprise web portal.

Table 1 highlights comparing points of all the methodologies mentioned in this paper. This comparison were made on the basis of the seven evaluation criteria developed through reviewing existing literatures of general ontology development and supply chain management [8].

As far the ontology-based interoperability within textile supply chain is concerned, several researchers have chosen UPON methodology as a more appropriate ontology development method than other methodologies [12, 24, 25, 47]. Also in a recent paper, Pourabbas and Taglino [46] have exploited UPON to develop an ontology within the ICT firms about the competencies of different enterprises. The advantages of UPON have been thoroughly discussed in Ref. [48] where it is shown that the adaptation of UPON is easy and requires very less technological threshold. UPON has its strong rooting in UML which enables diagramming, versioning and documentation with the assistance of various UML tools such as rationale rose, Microsoft visio, etc. [48]. A brief description of UPON is given as follows.

UPON is an approach that is derived from a wellestablished software engineering process-the unified software development process [49].

Software development unified process is a widespread and accepted method across the software engineers and UPON stems from process. It uses unified modeling language (UML) that is a rich and extensible language, and it gives UPON some distinguishable characteristics such as use-case drive, iterative and incremental nature [50].

The incremental nature of upon is represented by the sequential build-up of lexicon, glossary and thesaurus. Firstly the relevant terms of the domain are identified to form a lexicon, then definitions of the terms are attributed to develop a glossary. At the next stage, ontological relations are provided with for the terms thus thesaurus is produced.

UPON is segmented into cycles, phases, iterations and workflows, as shown in Fig. 1. Each cycle consists of four 
Table 1 Analysis of different ontology building methodologies [7]

\begin{tabular}{|c|c|c|c|c|}
\hline Name & $\begin{array}{l}\text { Level of } \\
\text { granularity }\end{array}$ & Industry sector & Aim & Applications \\
\hline Enterprise [41] & $\begin{array}{l}\text { Not } \\
\text { applicable }\end{array}$ & $\begin{array}{l}\text { No reference of } \\
\text { industry sector }\end{array}$ & $\begin{array}{l}\text { To enhancing human communication and } \\
\text { support interoperability }\end{array}$ & $\begin{array}{l}\text { Integration of software tools;bid analysis } \\
\text { process; market analysis;continuous } \\
\text { process improvement }\end{array}$ \\
\hline TOVE [20] & Strategic & $\begin{array}{l}\text { No reference of } \\
\text { industry sector }\end{array}$ & $\begin{array}{l}\text { To support the enterprise model } \\
\text { development so as to answer query in } \\
\text { industrial environment }\end{array}$ & $\begin{array}{l}\text { TOVT test bed to analyse enterprise } \\
\text { ontologies }\end{array}$ \\
\hline $\begin{array}{l}\text { Model of } \\
\text { Soares et al. } \\
\text { [42] }\end{array}$ & Strategic & $\begin{array}{l}\text { Electronics } \\
\text { (semiconductor) }\end{array}$ & $\begin{array}{l}\text { To improve communication necessary for } \\
\text { the identification, specification and } \\
\text { development of production planning and } \\
\text { control system to support a virtual } \\
\text { enterprise }\end{array}$ & No specific application has been reported \\
\hline IDEON [43] & Strategic & $\begin{array}{l}\text { No reference } \\
\text { industry sector }\end{array}$ & $\begin{array}{l}\text { To provide foundation for designing, } \\
\text { reinventing, managing and controlling } \\
\text { collaborative and distributed enterprises }\end{array}$ & $\begin{array}{l}\text { Crisis action planning and execution; } \\
\text { integrated product, process development }\end{array}$ \\
\hline $\begin{array}{l}\text { Manufacturing } \\
\text { system } \\
\text { engineering } \\
\text { ontology [44] }\end{array}$ & Strategic & Electronics & $\begin{array}{l}\text { Interoperability of manufacturing system } \\
\text { engineering applications as well as } \\
\text { knowledge reuse within globally extended } \\
\text { enterprises }\end{array}$ & $\begin{array}{l}\text { Ontology was implemented to enable } \\
\text { interoperability for inter-enterprise } \\
\text { collaboration }\end{array}$ \\
\hline $\begin{array}{l}\text { Model by Ye } \\
\text { et al. [45] }\end{array}$ & Strategic & $\begin{array}{l}\text { No reference } \\
\text { industry sector }\end{array}$ & $\begin{array}{l}\text { Enabling semantic integration between } \\
\text { heterogeneous systems in a supply chain }\end{array}$ & $\begin{array}{l}\text { The framework was implement on an } \\
\text { imaginary supply chain scenario and } \\
\text { solved the problem of information } \\
\text { integration }\end{array}$ \\
\hline UPON [40] & Strategic & Textile industry & Provide interoperability & $\begin{array}{l}\text { In textile factory for intra-enterprise } \\
\text { interoperability via semantic search of } \\
\text { products [24]. Also in ICT domain for } \\
\text { interoperability among different softwares } \\
\text { [45] }\end{array}$ \\
\hline $\begin{array}{l}\text { Methontology } \\
\text { [37] }\end{array}$ & $\begin{array}{l}\text { Strategic, } \\
\text { tactical, } \\
\text { operational }\end{array}$ & $\begin{array}{l}\text { Chemical batch } \\
\text { process }\end{array}$ & $\begin{array}{l}\text { Integration of design and planning of } \\
\text { supply chain together with the scheduling } \\
\text { of the plant }\end{array}$ & $\begin{array}{l}\text { In chemical batch process for providing } \\
\text { greater efficiency in communication, } \\
\text { integrating different software tools, and } \\
\text { easing decision making process. }\end{array}$ \\
\hline
\end{tabular}

phases and each phase is divided into several iterations. Each iteration again is branched into five workflows. Completion of one cycle generates a new version of ontology [40, 48].

At the inception phase, knowledge or the concepts are captured and during the elaborations phase concepts are analysed, identified and structured loosely. This construction phase takes place next when most of designs and implementation parts of the workflows are accomplished. Testing is carried out during the final phase and after satisfactory testing, and the ontology is released [25]. Flowchart of UPON is shown in Fig. 2.

UPON serves both human and automated systems and exploration of UPON is done by the human interaction which takes place through use-cases. During the life-cycle of UPON, each activity is repeated with the aim to develop the ontology which demonstrates its iterative nature. Again the ontology is refined and extended by every cycle which demonstrates its incremental nature [40, 48].

\section{Model trial}

After reviewing the challenges and issues found in the UPON and other methods, to be successful within this market, businesses will have to implement strategies by adopting solutions for improvement. Referring to the literature, the paper has developed potential solutions in order to overcome the problem of ineffective communication in relationship management. This challenge can be addressed by formalizing collaboration standards and methods, identifying common enterprise notions and mapping them to a general body of knowledge, namely, enterprise models. Hence, the relevant systems, based on those models, will become fully semantically interoperable. Mapping is a process in which implicit semantics of a database schema is mapped to the explicit and formal knowledge structure of the ontology. A database schema is used to generate a formal structure while preserving the logical mappings between ER meta-model and generated local ontology. 


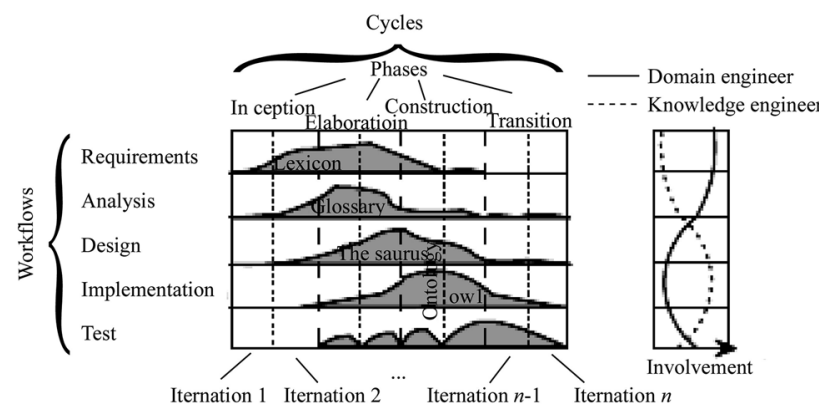

Fig. 1 UPON developing techniques [39]

Three solutions have been listed: (1) interoperability with focus on corporate strategies, (2) interoperability with focus on improving relationship management, and (3) interoperability with focus on collaboration of suppliers. The comparison of these three solutions is listed in Table 2.

Solution 1 is to build e-supply chain management into corporate strategy. A clear and well-defined supply chain strategy should be set and implemented by senior managers, firstly outlining clear strengths and weaknesses within the supply chain, followed by defined plans for improvement. The strategy must be prior setting and appropriate allocation of resources throughout the whole supply chain in order to achieve strategic outcomes [51]. This needs to be effectively communicated to staff and partners along the e-supply chain so that there is a greater understanding of how the strategic goals will be achieved. Supply chain will allow access to an extended network of suppliers, manufacturers, retailers and suppliers, which in turn gives scope for greater opportunities within the supply chain.

Solution 2 is focused on better management of relationships within the supply chain. This is derived from "Higher uncertainty through dynamic market structures...place a stronger emphasis on relationship management in order to secure these resources, capabilities, and strategies" [52]. Relationships and communication between managers and suppliers are vital-the flow of information in the supply chain needs to be effective and efficient (not operational and fragmented), otherwise supply-chain-wide benefits will not be reached [53]. Improved communication and information flow will also help to prevent mistakes and therefore minimize waste saving unnecessary costs. If there is effective communication between supply chain stakeholders, managers and suppliers, it will open up access to more flows of information and materials, which can be a source of competitive advantage and differentiation. "Information is the life blood of supply chain management...with accurate and near real time information, the disparate elements in supply chains can integrate their efforts to the benefit of the whole chain and eventually the end consumer" [54]. Improved relationship management and communication can improve the speed, agility and time

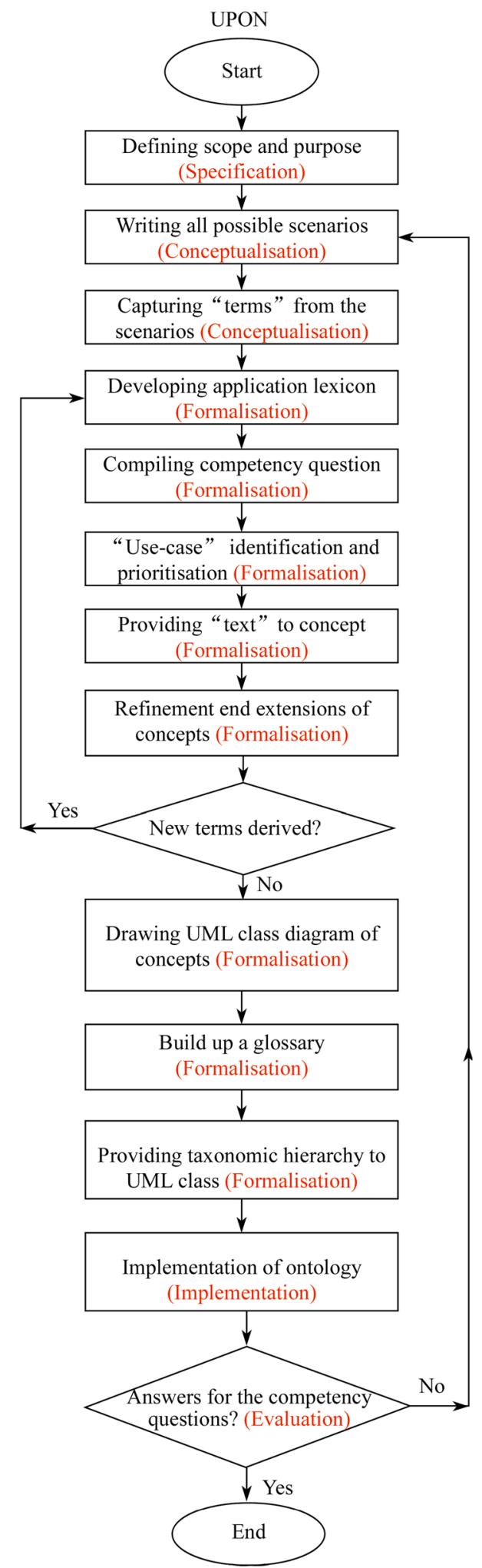

Fig. 2 UPON development flow-chart

control within the supply chain and therefore ultimately impact upon an improved customer experience and increased satisfaction. 
Table 2 Comparison of three solutions

\begin{tabular}{|c|c|c|}
\hline & Similarities & Differences \\
\hline \multirow[t]{2}{*}{ Solution 1} & Both rely on real-time reporting to create transparency & $\begin{array}{l}\text { Collaboration is specifically focused on two } \\
\text { or more partners working together }\end{array}$ \\
\hline & $\begin{array}{l}\text { E-SCM allows access to an extended network for collaboration } \\
\text { Both can improve supply chain efficiency }\end{array}$ & E-SCM involves the entire supply chain network \\
\hline Solution 2 & $\begin{array}{l}\text { E-SCM incorporates relationship management } \\
\text { Both promote Advanced information flow and visibility } \\
\text { Both develop information systems }\end{array}$ & $\begin{array}{l}\text { Relationship management is communication orientated } \\
\text { E-SCM focuses on flow of materials }\end{array}$ \\
\hline \multirow[t]{2}{*}{ Solution 3} & Both rely on effective communication & $\begin{array}{l}\text { Relationship management is important internally } \\
\text { and between external partners }\end{array}$ \\
\hline & Both can give opportunities to an extended network & Collaboration is essential between external partners \\
\hline
\end{tabular}

Solution 3 is the collaboration of supply chain partners. Collaboration involves working together with two or more partners, in order to achieve a shared goal, for example manufacturers, suppliers and retailers. The fundamental construct of e-SCM is to foster an e-collaboration environment where members in supply chains can work together in a more efficient and effective way by using internet technology [54]. Hoek [53] defined e-collaboration as "internet enabled collaborative channel partnerships". Collaboration of supply chain members means that there are greater levels of co-ordination, flexibility and stability. It is important that all supply chain partners view collaboration as a strategic asset, and this can be encouraged by building greater trust among trading partners. Collaborative commerce, integrated processes and information sharing throughout members of a supply chain can result in improvements such as shorter cycle times, minimal delays, and lower inventories, all leading to reduced costs and a more efficient supply chain. When two supply chain members collaborate, they benefit from an improved information flow and alignment of goals, which improves relationships between the two firms, allowing them to work together more effectively.

E-SCM strategy can be worked to foster a collaboration environment, where members in supply chains can work together to become efficient and effective. They both rely on real-time reporting and information systems in order to create transparency and build strong relationships. E-SCM opens opportunities for collaboration with an extended network of manufacturers, suppliers and retailers.

Collaboration within the supply chain is focused specifically on two or more partners working together whereas e-SCM involves an entire supply chain network, both upsteam and downstream in the supply chain. Works towards bringing all of the stages in the business cycle together relationship management allows more effective and efficient information flow via ICT, resulting in better communications and relationships between managers and suppliers. This can also be incorporated into an e-SCM strategy. Both solutions encourage more effective communication throughout the supply chain and lead to greater responsiveness which is essential in a volatile market. Relationship management is focused specifically on improving communications between managers and suppliers whereas e-SCM also focuses on the flow of materials along the supply chain.

Both relationship management and collaboration rely on effective communication between supply chain members, and without communication they will not be able to collaborate and work together effectively. Both solutions allow access to greater opportunities due to better relationships across an extended network of suppliers, retailers, etc. Relationship management can be focused both internally within the specific company and also with external partners who they will work with. Collaboration focuses on working with external partners.

If businesses were to adhere to one, or a combination of the discussed solutions, they would observe a variation of advantages and disadvantages in their supply chain, depending how successfully they strategically employed the solutions. Table 3 illustrates the strengths and weaknesses of each solution.

When implementing solution1: e-SCM into the supply chain, the key benefit results in greater information visibility. Moreover, information is used as a long-term resource for innovation, enhanced consumer relations and service propositions [52]. If a company improves its relationship management (see solution 2), suppliers and managers can formulate more accurate predictions. This can result in less out of stock inventory thus improving customer loyalty and gaining a larger consumer base. Adopting in a combination of these solutions can result in benefits such as higher transparency, reduced transaction, manufacturing costs, reduced unmonitored corporate spending and more centralised purchasing spend [55]. Furthermore, the supply chain can become more integrated, and the supply chain partners working together can save costs and lead to eventual increased profits. Golicic [52] 
Table 3 Advantages and disadvantages of three solutions

\begin{tabular}{|c|c|c|}
\hline Solutions & Advantages & Disadvantages \\
\hline $\begin{array}{c}\text { Solution } \\
1\end{array}$ & $\begin{array}{l}\text { Greater information } \\
\text { visibility helps managers } \\
\text { plan, execute and } \\
\text { evaluate results with } \\
\text { greater precision and } \\
\text { speed }\end{array}$ & $\begin{array}{l}\text { Information overload, } \\
\text { companies have access to } \\
\text { more information than } \\
\text { they accustomed to } \\
\text { managing }\end{array}$ \\
\hline $\begin{array}{l}\text { Solution } \\
2\end{array}$ & $\begin{array}{l}\text { Better communication } \\
\text { skills, formulate more } \\
\text { accurate predictions }\end{array}$ & $\begin{array}{l}\text { Organizational } \\
\text { misunderstanding and } \\
\text { poor coordination of } \\
\text { information with } \\
\text { decision-making needs }\end{array}$ \\
\hline $\begin{array}{c}\text { Solution } \\
3\end{array}$ & $\begin{array}{l}\text { Partners can collaborate } \\
\text { more intensely around } \\
\text { market opportunities }\end{array}$ & $\begin{array}{l}\text { Communication problems } \\
\text { and difficulties in } \\
\text { aligning the processes of } \\
\text { partner companies }\end{array}$ \\
\hline
\end{tabular}

adds validity to this, stating that companies have transformed information visibility into competitive advantage.

Greater information visibility in the supply chain can lead to disadvantages, such as information overload, as companies have access to more information that they are accustomed to managing, potentially resulting in confusion and additional uncertainty [52]. Buchanan and Gibb [55] outline other disadvantages that are as a result from pursuing in the suggested solutions, such as information overload, organizational misunderstanding of the role of information management, inadequate locator tools and poor coordination of information with decision-making needs.

There can be communication problems and difficulties in aligning the processes and cultures of partner companies, as well as differences in supply chain partners goals and aims. If in a business there is insufficient leadership, there will be an unwillingness to cooperate and negotiate. This can result in a lack of trust and lead to personal insecurity with individual supply chain partners. It can be time-consuming and complex to implement new procedures and therefore make it difficult to achieve the ultimate aims. There are constant updates in technology and because of this, lack of resources and the plethora of different standards is commonly found in businesses. Furthermore, there can be an "unwillingness to cooperate, fear of losing jobs and a threat of being by-passed by technology" from members within the supply chain [56].

\section{Conclusions}

Scenario of textile supply in today's business world is global where different participating enterprises along the supply chain are situated in geographically different locations. To survive in this global textile market, e-business is now being considered as an essential solution which can bring many-fold benefits to the supply chain. Development and successful implementation of e-business solutions imply essentiality of enterprise integration. Textile supply chain is comprised of many large, medium and small industries, and the collaboration of enterprises are hindered by communication problems among enterprises for being heterogeneous.

Several researches show that implementation of ERP systems cannot successfully resolve the interoperability issue rather the need of enterprise integration has been amplified. As an efficient solution, semantic interoperability via ontology-based framework has been applied in several supply chains including textile supply chain.

Regarding the ontology development method, UPON has been found to be effective among other methodologies as its development cycle appears to be more suitable for the supply chain domains especially for textiles.

On the basis of existing empirical studies, this paper postulates that an ontology-based interoperability framework improves the interoperability between the buyers and suppliers of textile supply chain and reduces the production lead time of a textile manufacturing plant. In addition, automatic cost estimation of textile products and value proposition of enterprises have also been shown as benefits that can be derived from ontology-based interoperability. In future, empirical studies will be carried out within textile supply chain domain to establish the factuality of the arguments about the benefits of ontology-based interoperability implementation.

\section{References}

1. Ramdas K, Spekman RE (2000) Chain or shackles: understanding what drives supply-chain performance. Interfaces 30(4):3-21

2. Frohlich MT, Westbrook R (2001) Arcs of integration: an international study of supply chain strategies. J Oper Manag 19(2): 185-200

3. Rosenzweig ED, Roth AV, Dean JW Jr (2003) The influence of an integration strategy on competitive capabilities and business performance: an exploratory study of consumer products manufacturers. J Oper Manag 21(4):437-456

4. Cagliano R, Caniato F, Spina G (2004) Lean, agile and traditional supply: how do they impact manufacturing performance? J Purch Supply Manag 10(4):151-164

5. Teng SG, Jaramillo H (2006) Integrating the US textile and apparel supply chain with small companies in South America. Supply Chain Manag Int J 11(1):44-55

6. Handfield RB, Nichols EL (1999) Introduction to supply chain management, vol 183. Prentice Hall, Upper Saddle River

7. Muñoza E, Capón-Garcíab E, Miguel LJ et al (2013) Integration of enterprise levels based on an ontological framework. Chem Eng Res Des 91(8):1542-1556

8. Grubic T, Fan I-S (2010) Supply chain ontology: review, analysis and synthesis. Comput Ind 61(8):776-786 
9. Kumar K (2001) Technology for supporting supply chain management: introduction. Commun ACM 44(6):58-61

10. Buxmann P et al (2004) Usage and evaluation of supply chain management software-results of an empirical study in the European automotive industry. Inf Syst J 14(3):295-309

11. Gunasekaran A, Ngai EW (2004) Information systems in supply chain integration and management. Eur J Oper Res 159(2):269295

12. Gessa N et al (2003) MODAML, an interoperability framework for the textile-clothing sector. In: IADIS international conference

13. IEEE office (1990) IEEE standard glossary of software engineering terminology. $\mathrm{p} 43$

14. Guo J, Hu Z (2008) Common textile vocabularies and documents. ICE-B 2008, p 81

15. Davenport TH, Brooks JD (2004) Enterprise systems and the supply chain. J Enterp Inf Manag 17(1):8-19

16. Hillegersberg Jv, Kumar K (2000) ERP experience and evolution. Commun ACM 43(4):23-26

17. Akkermans HA et al (2003) The impact of ERP on supply chain management: exploratory findings from a European Delphi study. Eur J Oper Res 146(2):284-301

18. Cagliano R, Caniato F, Spina G (2006) The linkage between supply chain integration and manufacturing improvement programmes. Int J Oper Prod Manag 26(3):282-299

19. Pant S, Sethi R, Bhandari M (2003) Making sense of the e-supply chain landscape: an implementation framework. Int J Inf Manage 23(3):201-221

20. Uschold M, Gruninger M (1996) Ontologies: principles, methods and applications. Knowl Eng Rev 11(2):93-136

21. Smith B, Welty C (2001) Ontology: towards a new synthesis. In: Formal ontology in information systems. ACM Press, New York, pp iii-x

22. Guarino N (1998) Formal onthology in information systems: proceedings of the first international conference [FIOS'98], vol 46, June 6-8, Trento, Italy

23. Kishore R, Sharman R, Ramesh R (2004) Computational ontologies and information systems: I. foundations. Commun Assoc Inf Syst 14:158-183

24. De Sabbta P et al (2006) Providing a semantic description for an interoperability framework using ontologies. pp 197-204

25. Duque A et al (2009) An ontological solution to support interoperability in the textile industry. Springer, pp 38-51

26. Gruber TR (1995) Toward principles for the design of ontologies used for knowledge sharing. Int J Hum Comput Stud 43(5):907-928

27. Pinto HS, Martins JP (2004) Ontologies: how can they be built? Knowl Inf Syst 6(4):441-464

28. Berge J (1991) The EDIFACT standards. Wiley-Blackwell

29. TEDIS TE (1992) Systems programme, interim report. Office for official publications of the European Community, ISBN-92-8265658-6

30. Robinet P, Dufour J. HLQ: description of the eTeXML project, Annex

31. TEX-WEAVE. Available from: http://www.texweave.org/

32. Dogac A et al (2008) iSURF: an interoperability service utility for collaborative supply chain planning across multiple domains. In: Proceedings of the eChallanges conference, Stockholm

33. Spohrer J, Kwan SK (2009) Service science, management, engineering, and design (SSMED): An emerging discipline-outline \& references. Int J Inf Syst Serv Sect 1(3):1-31

34. Hofman W (2011) Design of large-scale enterprise interoperable value webs. In: Workshop on the move to meaningful Internet systems, pp 122-135

35. Ponn J, Lindemann U (2006) Intelligent search for product development information-an ontology-based approach. In:
Marjanovic D (ed) 9th international design conference, Dubrovnik, Croatia

36. Lemaignan $\mathrm{S}$ et al (2006) MASON: a proposal for an ontology of manufacturing domain. In: IEEE workshop on distributed intelligent systems: collective intelligence and its applications, Prague, 15-16 June 2006

37. Fernández-López M, Gómez-Pérez A (2002) Overview and analysis of methodologies for building ontologies. Knowl Eng Rev 17(2):129-156

38. IEEE (1997) IEEE standard for developing software life-cycle process. In: IEEE Std 1074-1997, USA

39. Rajpathak D, Chougule R (2011) A generic ontology development framework for data integration and decision support in a distributed environment. Int J Comput Integr Manuf 24(2):154-170

40. De Nicola A, Missikoff M, Navigli R (2005) A proposal for a unified process for ontology building: UPON. In: Database and expert systems applications. Springer

41. Uschold M et al (1998) The enterprise ontology. Knowl Eng Rev 13(01):31-89

42. de Sousa JP (2000) Distributed planning and control systems for the virtual enterprise: organizational requirements and development life-cycle. J Intell Manuf 11(3):253-270

43. Madni AM, Lin W, Madni CC (2001) IDEONTM: an extensible ontology for designing, integrating, and managing collaborative distributed enterprises. Syst Eng 4(1):35-48

44. Lin H-K, Harding JA, Shahbaz M (2004) Manufacturing system engineering ontology for semantic interoperability across extended project teams. Int J Prod Res 42(24):5099-5118

45. Ye Y et al (2008) An ontology-based architecture for implementing semantic integration of supply chain management. Int $\mathrm{J}$ Comput Integr Manuf 21(1):1-18

46. Pourabbas E, Taglino F (2012) A semantic platform for enterprise knowledge interoperability. In: Poler $\mathrm{R}$ et al (ed) Enterprise interoperability V. Springer, London, pp 119-128

47. Gessa $N$ et al (2006) Extracting a semantic view from an ebusiness vocabulary. In: The 8th IEEE international conference on and enterprise computing and the 3rd IEEE international conference on E-commerce, and E-services. San Francisco, USA, 26-29 June 2006

48. de Nicola A, Missikoff M, Navigli R (2009) A software engineering approach to ontology building. Inf Syst 34(2):258-275

49. Jacobson I (1999) The unified software development process. 1st edn. Addison-Wesley Professional, US

50. Guizzardi G, Herre H, Wagner G (2002) Towards ontological foundations for UML conceptual models. In: On the move to meaningful internet systems 2002: CoopIS, DOA, and ODBASE. Springer, pp 1100-1117

51. Daft R, Kendrick M, Vershinna N (2010) Management, 9th edn., Chap. 8. Cengage Learning EMEA, Hampshire

52. Golicic S, Davis D, McCarthy T, Mentzer J (2002) The impact of e-commerce on supply chain relationships. Int J Phys Distribution Logist Manag 32(10)851-871

53. Hoek R (2001) E-supply chains-virtually non-existing. Supply Chain Manag Int J 6(1):21-28

54. Slack N, Chambers S, Johnston R (2007) Operations management, 5th edn. Pearson Education Limited, Essex, pp 423-424

55. Buchanan S, Gibb F (1998) The information audit: an integrated strategic approach. Int J Inf Manag 18(I)

56. Wagner C, Sweeney E (2010) E-business in supply chain management. In: Electronic supply network coordination in intelligent and dynamic environments, modelling and Hershey, PA: IGI Global, Chap 2, pp 24-42 